\title{
A New Score to Predict the Resectability of Pancreatic Adenocarcinoma: The BACAP Score
}

\author{
Charlotte Maulat ${ }^{1,2, *(\mathbb{0})}$, Cindy Canivet ${ }^{3}$, Célia Touraine ${ }^{4}$, Sophie Gourgou ${ }^{4}$, \\ Bertrand Napoleon ${ }^{5}$, Laurent Palazzo ${ }^{6}$, Nicolas Flori ${ }^{7}$, Guillaume Piessen ${ }^{8,9}{ }^{\circ}$, \\ Pierre Guibert ${ }^{10}$, Stéphanie Truant ${ }^{11}{ }^{1}$, Eric Assenat ${ }^{12}$, Louis Buscail ${ }^{2,3}{ }^{\mathbb{D}}$, Barbara Bournet ${ }^{2,3}$, \\ Fabrice Muscari ${ }^{1,2}{ }^{-}$and the BACAP Consortium ${ }^{\dagger}$
}

1 The Digestive Surgery and Liver Transplantation Department, Toulouse University Hospital, 31400 Toulouse, France; muscari.f@chu-toulouse.fr

2 INSERM U1037, The Toulouse Cancer Research Center, Toulouse University, 31100 Toulouse, France; buscail.1@chu-toulouse.fr (L.B.); bournet.b@chu-toulouse.fr (B.B.)

3 The Gastroenterology and Pancreatology Department, Toulouse University Hospital, 31400 Toulouse, France; canivet.c@chu-toulouse.fr

4 Biometrics Unit, Montpellier Cancer Institute, University of Montpellier, 34000 Montpellier, France; celia.touraine@icm.unicancer.fr (C.T.); sophie.gourgou@icm.unicancer.fr (S.G.)

5 The Jean Mermoz private hospital, Ramsay Général de Santé, 69008 Lyon, France; bertrand.napoleon@dartybox.com

6 Trocadero Clinic, 75116 Paris, France; laurent.palazzo@wanadoo.fr

7 The Gastroenterology Department, Montpellier Cancer Institute, University of Montpellier, 34000 Montpellier, France; nicolas.flori@montpellier.unicancer.fr

8 Department of Digestive and Oncological Surgery, Lille University Hospital, 59000 Lille, France; guillaume.piessen@chru-lille.fr

9 CANTHER laboratory "Cancer Heterogeneity, Plasticity and Resistance to Therapies" UMR-S1277 INSERM, Team "Mucins, Cancer and Drug Resistance", 59000 Lille, France

10 The Léon Bérard Center, 69008 Lyon, France; pierre.guibert@lyon.unicancer.fr

11 Department of Digestive Surgery and Transplantations, Lille University Hospital, 59000 Lille, France; stephanie.truant@chru-lille.fr

12 The Saint Eloi Hospital, University Hospital, 34000 Montpellier, France; e-assenat@chu-montpellier.fr

* Correspondence: maulat.c@chu-toulouse.fr; Tel.: +33-561-322-741

+ Membership of the BACAP Consortium is provided in the Acknowledgement.

Received: 26 February 2020; Accepted: 22 March 2020; Published: 25 March 2020

\begin{abstract}
Surgery remains the only curative treatment for pancreatic ductal adenocarcinoma (PDAC). Therefore, a predictive score for resectability on diagnosis is needed. A total of 814 patients were included between 2014 and 2017 from 15 centers included in the BACAP (the national Anatomo-Clinical Database on Pancreatic Adenocarcinoma) prospective cohort. Three groups were defined: resectable (Res), locally advanced (LA), and metastatic (Met). Variables were analyzed and a predictive score was devised. Of the 814 patients included, 703 could be evaluated: 164 Res, 266 LA, and 273 Met. The median ages of the patients were 69,71 , and 69 , respectively. The median survival times were 21 , 15 , and nine months, respectively. Six criteria were significantly associated with a lower probability of resectability in multivariate analysis: venous/arterial thrombosis $(p=0.017)$, performance status $1(p=0.032)$ or $\geq 2(p=0.010)$, pain $(p=0.003)$, weight loss $\geq 8 \%(p=0.019)$, topography of the tumor (body/tail) $(p=0.005)$, and maximal tumor size $20-33 \mathrm{~mm}(p<0.013)$ or $>33 \mathrm{~mm}(p<0.001)$. The BACAP score was devised using these criteria with an accuracy of $81.17 \%$ and an area under the receive operating characteristic (ROC) curve of 0.82 ( $95 \%$ confidence interval (CI): $0.78 ; 0.86$ ). The presence of pejorative criteria or a BACAP score $<50 \%$ indicates that further investigations and even neoadjuvant treatment might be warranted. Trial registration: NCT02818829.
\end{abstract}


Keywords: pancreatic ductal adenocarcinoma; pancreatic cancer; predictive factors; resectability; locally advanced; metastasis; BACAP cohort; score

\section{Introduction}

Pancreatic ductal adenocarcinoma (PDAC) remains a major world health concern as it is the third most common cause of death due to cancer in Western countries. By 2030, it is projected to be the second leading cause of death due to cancer $[1,2]$. The five-year survival for all stages is very low $(7 \%$ to $8 \%$ ) $[1,3,4]$ and surgery is still the only curative treatment, although this is only possible in $15 \%$ to $20 \%$ of the cases [5]. The poor prognosis for PDAC did not improve over the past several decades even in resectable patients; the mean overall survival is not significantly different for the 1980s (23.2 months), 1990s (25.6 months), and 2000s (24.5 months) [6-8].

Of the remaining $80-85 \%$ patients who are unresectable due to locally advanced disease, vascular invasion, or metastases, up to $30 \%$ are found to be inoperable during explorative laparotomy $[9,10]$. Recently, in France, the use of preoperative diffusion MRI to detect liver metastases changed the management and frequency of unnecessary laparotomies and pancreatectomies for $10 \%$ of the potentially resectable PDAC patients [11]. However, despite improvements in imaging, there is still a need to identify and combine clinico-radiological prognostic factors to help physicians stage the disease early in its course and devise and implement the optimal treatment [12].

Several authors attempted to identify predictive factors of PDAC resectability on diagnosis. Preoperative carbohydrate antigen 19-9 (CA 19-9), the maximal tumor size, and location in the body and tail of the pancreas are the main predictive factors for poor PDAC resectability [13-19]. However, most of these studies focused on only one or two predictive factors, mainly retrospectively, which resulted in clear biases. Therefore, a large prospective cohort should be established to study a range of predictive factors of PDAC resectability.

To address the lack of clinico-radiological and biological PDAC data, a French multicenter cohort named "BACAP" (the national Anatomo-Clinical Database on Pancreatic Adenocarcinoma), which includes clinical and epidemiological data linked to biological samples of PDAC patients, was developed [20]. This unique large multicenter cohort is a "snapshot" of the current management and outcomes of patients with PDAC in France. The BACAP cohort (universities or private hospitals) has a high level of representativeness of current practices in terms of the diagnosis and treatment of PDAC patients in France.

The aim of this study was to use the data from the BACAP cohort to determine the profile of patients with resectable PDAC and to develop the first predictive scoring system to determine PDAC resectability on diagnosis, using clinico-radiological criteria.

\section{Results}

\subsection{Patients}

Between May 2014 and July 2017, 814 patients with histologically and/or cytologically proven PDAC were included in the BACAP cohort. In the univariate analysis, 703 patients were included: 164 patients $(23 \%)$ in the resectable (Res) group, 266 patients (38\%) in the locally advanced (LA) group, and 273 patients (39\%) in the metastatic (Met) group. After exclusion of the patients with more than $20 \%$ of missing data, 515 patients were included in the multivariate analysis: 114 patients (22\%) in the Res group, 213 patients (41\%) in the LA group, and 188 patients (37\%) in the Met group (Figure 1). 


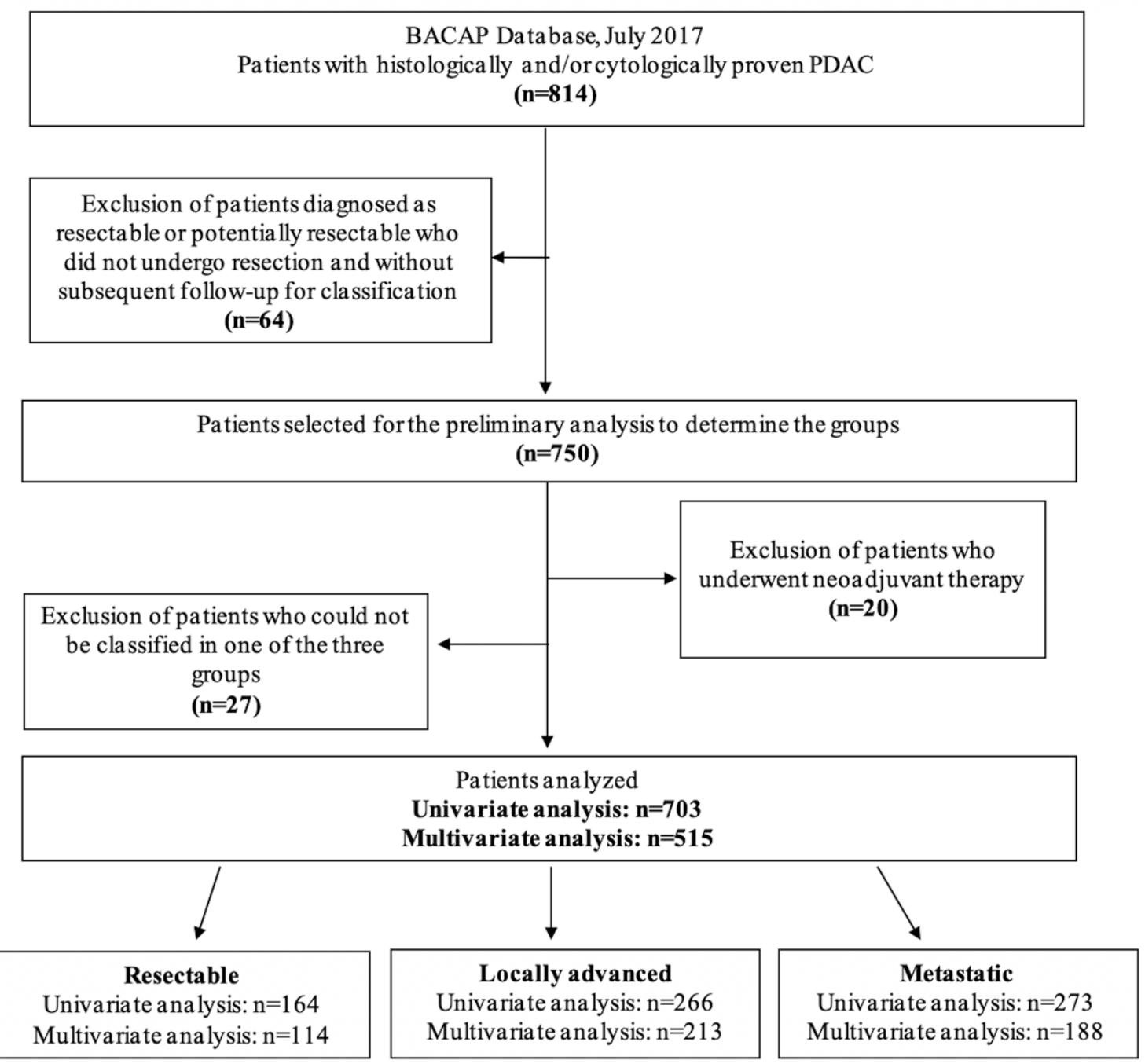

Figure 1. Flowchart. BACAP: National Anatomo-Clinical Database on Pancreatic Adenocarcinoma; PDAC: pancreatic ductal adenocarcinoma.

\subsection{Baseline Characteristics}

The baseline characteristics are listed in Table 1 (univariate analysis). The presence of venous or arterial thrombosis, weight loss, abdominal pain, and a WHO (World Health Organization) performance status score $\geq 2$, as well as the level of carbohydrate antigen 19-9 (CA 19-9) or carcinoembryonic antigen (CEA) and the maximal tumor size (with higher values in the locally advanced and metastatic groups), were significantly different between the groups $(p<0.001)$. 
Table 1. PDAC patient characteristics at baseline (univariate analysis).

\begin{tabular}{|c|c|c|c|c|c|}
\hline $\begin{array}{l}\text { PDAC Patient Characteristics at Baseline } \\
\text { (Univariate Analysis) }\end{array}$ & $\operatorname{Res}(n=164)$ & LA $(n=266)$ & Met $(n=273)$ & Total $(n=703)$ & $p$ \\
\hline \multicolumn{6}{|c|}{ Demographic Data } \\
\hline Age on diagnosis (median, range) (MD) & $69(21-88)(0)$ & $71(34-91)(0)$ & $69(36-91)(0)$ & $70(21-91)(0)$ & 0.070 \\
\hline Gender (n, \%) (MD) & & & & & 0.408 \\
\hline Female & $73(44.5)(0)$ & $129(48.5)(0)$ & $117(42.9)(0)$ & $319(45.4)(0)$ & \\
\hline Male & $91(55.5)(0)$ & $137(51.5)(0)$ & $156(57.1)(0)$ & $384(54.6)(0)$ & \\
\hline $\begin{array}{l}\text { Body mass index on diagnosis (median, } \\
\text { range) (MD) }\end{array}$ & $24.4(15-52)(3)$ & $\begin{array}{c}23.5 \\
(15.6-114.3)(5)\end{array}$ & $\begin{array}{c}24.1(14.2-112) \\
(13)\end{array}$ & $\begin{array}{c}23.9 \\
(14.2-114.3)(21)\end{array}$ & 0.05 \\
\hline \multicolumn{6}{|c|}{ Medical History } \\
\hline WHO performance status (n, \%) (MD) & & & & & $<0.001$ \\
\hline 0 & $76(58.9)(35)$ & $86(36.3)(29)$ & $88(37.1)(36)$ & $250(41.5)(100)$ & \\
\hline 1 & $48(37.2)(35)$ & $124(52.3)(29)$ & $101(42.6)(36)$ & $273(45.3)(100)$ & \\
\hline$\geq 2$ & $5(3.9)(35)$ & 27 (11.4) (29) & 48 (20.3) (36) & $80(13.3)(100)$ & \\
\hline Smoking history (n, \%) (MD) & & & & & 0.097 \\
\hline Non-smoker & $76(46.3)(0)$ & $145(54.9)(2)$ & $131(49.1)(6)$ & $352(50.7)(8)$ & \\
\hline Former smoker & $46(28.1)(0)$ & $75(28.4)(2)$ & $89(33.3)(6)$ & $210(30.2)(8)$ & \\
\hline Current smoker & $42(25.6)(0)$ & $44(16.7)(2)$ & $47(17.6)(6)$ & $133(19.1)(8)$ & \\
\hline Alcohol consumption (n, \%) (MD) & & & & & 0.791 \\
\hline Non-consumer & $100(61.4)(1)$ & $174(66.4)(4)$ & $179(66.5)(4)$ & $453(65.3)(9)$ & \\
\hline Former consumer & $17(10.4)(1)$ & $21(8.0)(4)$ & $24(8.9)(4)$ & $62(8.9)(9)$ & \\
\hline Current consumer & $46(28.2)(1)$ & $67(25.6)(4)$ & $66(24.5)(4)$ & $179(25.8)(9)$ & \\
\hline Family history of cancer (n, \%) (MD) & $66(40.2)(0)$ & $123(46.2)(0)$ & $128(47.1)(1)$ & $317(45.2)(1)$ & 0.346 \\
\hline Diabetes (n, \%) (MD) & $44(26.8)(0)$ & $74(27.8)(0)$ & $61(22.4)(1)$ & 179 (25.5) (1) & 0.323 \\
\hline \multirow[t]{2}{*}{ Other pancreatic diseases * $(n, \%)(M D)$} & $30(18.3)(0)$ & $20(7.5)(0)$ & $15(5.5)(0)$ & $65(9.3)(0)$ & $<0.001$ \\
\hline & \multicolumn{4}{|c|}{ Clinical condition on diagnosis } & \\
\hline Venous or arterial thrombosis (n, \%) (MD) & $7(4.3)(0)$ & $39(14.7)(0)$ & $51(18.7)(0)$ & $97(13.8)(0)$ & $<0.001$ \\
\hline Weight loss (n, \%) (MD) & $90(55.6)(2)$ & $200(76.1)(3)$ & $186(68.6)(2)$ & 476 (68.4) (7) & $<0.001$ \\
\hline Abdominal pain (n, \%) (MD) & $89(54.3)(0)$ & $193(72.8)(1)$ & $201(73.9)(1)$ & $483(69)(2)$ & $<0.001$ \\
\hline Jaundice (n, \%) (MD) & $80(48.8)(0)$ & $116(43.8)(1)$ & $68(25)(1)$ & $264(37.7)(2)$ & $<0.001$ \\
\hline \multirow[t]{2}{*}{ Acute pancreatitis (n, \%) (MD) } & $19(11.6)(0)$ & $11(4.2)(2)$ & $8(2.9)(1)$ & $38(5.4)(3)$ & $<0.001$ \\
\hline & \multicolumn{5}{|c|}{ Tumor Characteristics and Procedures } \\
\hline $\begin{array}{l}\text { Maximal tumor size (mm) (median, range) } \\
\text { (MD) }\end{array}$ & $27(7-76)(15)$ & $35(4-85)(10)$ & $36(2-150)(12)$ & $33(2-150)(37)$ & $<0.001$ \\
\hline $\begin{array}{l}\text { Tumor location: head of pancreas (n, \%) } \\
\text { (MD) }\end{array}$ & $117(72.2)(2)$ & $169(63.8)(1)$ & $125(47)(7)$ & $411(59.3)(10)$ & $<0.001$ \\
\hline Biliary drainage (\%) (MD) & $60(36.6)(0)$ & $112(42.1)(0)$ & $69(25.3)(0)$ & $241(34.3)(0)$ & $<0.001$ \\
\hline \multirow[t]{2}{*}{$\begin{array}{c}\text { Surgical resection by } \\
\text { pancreaticoduodenectomy (n, \%) (MD) }\end{array}$} & $58(79.4)(0)$ & $0(0)$ & $0(0)$ & $58(8.3)(0)$ & - \\
\hline & \multicolumn{3}{|c|}{ Biology on Diagnosis } & & \\
\hline $\begin{array}{l}\text { Serum bilirubin }(\mu \mathrm{mol} / \mathrm{L})(\text { median, range) } \\
(\mathrm{MD})\end{array}$ & $\begin{array}{c}32.5(2.5-533.3) \\
(34)\end{array}$ & $32(3.4-647)(83)$ & $\begin{array}{l}12.8(3.4-548) \\
\quad(78)\end{array}$ & $\begin{array}{l}18.4(2.5-647) \\
(195)\end{array}$ & 0.004 \\
\hline CA 19-9 (IU/mL) (median, range) (MD) & $\begin{array}{c}183.5(0.1-5314) \\
(84)\end{array}$ & $\begin{array}{c}247.6 \\
(0-240000)(152)\end{array}$ & $\begin{array}{c}521.7 \\
(0-135720)(129)\end{array}$ & $\begin{array}{c}261.2 \\
(0-240000)(365)\end{array}$ & $<0.001$ \\
\hline CEA (IU/ml) (median, range) (MD) & $3(0.6-44.4)(99)$ & $\begin{array}{c}5(0.5-3862) \\
(177)\end{array}$ & $\begin{array}{c}11(0.7-11394) \\
(147)\end{array}$ & $\begin{array}{c}5.3(0.5-11394) \\
(423)\end{array}$ & $<0.001$ \\
\hline
\end{tabular}

Res: Resectable; LA: locally advanced; Met: metastatic; PDAC: pancreatic ductal adenocarcinoma; MD: missing data; CEA: carcinoembryonic antigen; CA 19-9: carbohydrate antigen 19-9; weight variation (\%): (weight on diagnosis usual weight)/usual weight $\times 100 .{ }^{*}$ Intraductal papillary mucinous tumor of the pancreas, mucinous cystadenoma, serous cystadenoma, chronic pancreatitis, and/or hereditary pancreatitis.

The presence of jaundice, location of the tumor in the head of the pancreas, and acute pancreatitis on diagnosis were also significantly different between the groups $(p<0.001)$, with a higher frequency in the Res group. In the Res group, pancreatoduodenectomy was performed in $79.4 \%$ of the cases. Biliary drainage was performed in $34.3 \%$ of the cohort. The main imaging examination to detect PDAC 
was abdominal CT scan in $75 \%$ of the cases, followed by ultrasound endoscopy fine-needle aspiration in $22 \%$ of the cases. There were no significant differences between the three groups in terms of the length of time between the onset of symptoms and the first radiological examination (36 days (0-2500) for the Res group, 41 days (0-750) for the LA group, and 37 days (0-404) for the Met group, $p=0.304$ ), or between the onset of symptoms and the pathological analysis (48 days (5-2500) for the Res group, 53.5 days (8-765) for the LA group, and 49 days (5-429) for the Met group, $p=0.09$ ).

\subsection{Clinico-Radiological Variables That Predict the Resectability Status}

The multivariate analysis identified six clinico-radiological factors that significantly reduced the probability of having a resectable tumor on diagnosis: the presence of venous or arterial thrombosis $(p=0.017)$, a WHO performance status score of 1 vs. $0(p=0.032)$ or $\geq 2(p=0.010)$ vs. 0 , weight loss $\geq 8 \%$ ( $p=0.019)$, abdominal pain $(p=0.003)$, location of the tumor in the body or the tail of the pancreas $(p=0.005)$, and a maximal tumor size between 20 and $33 \mathrm{~mm}(p=0.013)$ or more than $33 \mathrm{~mm}$ vs. $\leq 20 \mathrm{~mm}(p<0.001)$ (Table 2$)$.

Table 2. Predictive clinico-radiological factors of resectability (multivariate analysis).

\begin{tabular}{|c|c|c|c|}
\hline $\begin{array}{l}\text { Predictive Clinico-Radiological Factors of } \\
\text { Resectability (Multivariate Analysis) }\end{array}$ & OR & $95 \% \mathrm{CI}$ & $p$ \\
\hline \multicolumn{4}{|l|}{ Venous or arterial thrombosis on diagnosis } \\
\hline \multicolumn{4}{|l|}{ No } \\
\hline Yes & 0.30 & $0.11 ; 0.81$ & 0.017 \\
\hline \multicolumn{4}{|l|}{ WHO Performance Status on diagnosis } \\
\hline \multicolumn{4}{|l|}{0} \\
\hline 1 & 0.58 & $0.35 ; 0.95$ & 0.032 \\
\hline$\geq 2$ & 0.25 & $0.09 ; 0.72$ & 0.010 \\
\hline \multicolumn{4}{|l|}{ Weight loss on diagnosis } \\
\hline \multicolumn{4}{|l|}{$\leq 8 \%$} \\
\hline$\geq 8 \%$ & 0.55 & $0.34 ; 0.91$ & 0.019 \\
\hline \multicolumn{4}{|l|}{ Abdominal pain on diagnosis } \\
\hline \multicolumn{4}{|l|}{ No } \\
\hline Yes & 0.46 & $0.28 ; 0.76$ & 0.003 \\
\hline \multicolumn{4}{|l|}{ Location of the tumor } \\
\hline \multicolumn{4}{|l|}{ Head } \\
\hline Body and tail & 0.42 & $0.24 ; 0.75$ & 0.005 \\
\hline \multicolumn{4}{|l|}{ Maximal tumor size (mm) } \\
\hline \multicolumn{4}{|l|}{$\leq 20$} \\
\hline $20-33$ & 0.49 & $0.28 ; 0.86$ & 0.013 \\
\hline$>33$ & 0.11 & $0.05 ; 0.20$ & $<0.001$ \\
\hline
\end{tabular}

The biological data were not included in the multivariate analysis due to missing data, for statistical relevance.

\subsection{The Predictive Score (the BACAP Score)}

Based on these multivariate analysis results, we devised a predictive scoring system to determine PDAC resectability on diagnosis using the six clinico-radiological variables in Table 2 . The scoring 
system is detailed in Table 3, and a website was created to facilitate the use of this score and to enable routine use (http://jdlp.fr/resectability/). Using a cutoff value of 0.5 , the model predicted the resectability status in $81.17 \%$ of the cases and the area under the receiver operating characteristic (ROC) curve was 0.8205 (95\% confidence interval (CI): $0.78 ; 0.86)$.

Table 3. The BACAP score: the scoring system to determine the resectability of pancreatic ductal adenocarcinoma. Exp: exponential function.

\begin{tabular}{|c|c|c|}
\hline The BACAP Score & $x_{n}$ & $\beta_{\mathbf{i}}$ \\
\hline $\begin{array}{c}\text { Venous or arterial thrombosis on diagnosis: } x_{1} \\
\text { No } \\
\text { Yes }\end{array}$ & $\begin{array}{l}0 \\
1\end{array}$ & -1.21 \\
\hline $\begin{array}{c}\text { WHO Performance Status on diagnosis: } x_{2} \\
0 \\
1 \\
\geq 2\end{array}$ & $\begin{array}{l}0 \\
1 \\
2\end{array}$ & $\begin{array}{l}-0.55 \\
-1.37\end{array}$ \\
\hline $\begin{array}{l}\text { Weight loss on diagnosis: } x_{3} \\
\qquad 8 \% \text { on diagnosis } \\
\quad \geq 8 \% \text { on diagnosis }\end{array}$ & $\begin{array}{l}0 \\
1\end{array}$ & -0.59 \\
\hline $\begin{array}{c}\text { Abdominal pain on diagnosis: } x_{4} \\
\text { No } \\
\text { Yes }\end{array}$ & $\begin{array}{l}0 \\
1\end{array}$ & -0.77 \\
\hline $\begin{array}{l}\text { Location of the tumor: } x_{5} \\
\text { Head } \\
\text { Body and tail }\end{array}$ & $\begin{array}{l}0 \\
1\end{array}$ & -0.86 \\
\hline $\begin{array}{l}\text { Maximal tumor size: } x_{6} \\
\quad \leq 20 \mathrm{~mm} \\
20-33 \mathrm{~mm} \\
>33 \mathrm{~mm}\end{array}$ & $\begin{array}{l}0 \\
1 \\
2\end{array}$ & $\begin{array}{l}-0.70 \\
-2.25\end{array}$ \\
\hline
\end{tabular}

A multivariate logistic model with variables significant at a level of $5 \%$ was used to devise the following predictive score (Equation (1)):

$$
\text { Probability of resectability }(\%)=\left(\frac{1}{1+\exp \left\{-\left(\hat{\beta}_{0}+\hat{\beta}_{1} x_{1}+\hat{\beta}_{2} x_{2}+\hat{\beta}_{3} x_{3}+\hat{\beta}_{4} x_{4}+\hat{\beta}_{5} x_{5}+\hat{\beta}_{6} x_{6}\right)\right\}}\right) \times 100
$$

where $\hat{\beta}_{0}=1.28$ and $\hat{\beta}_{i}, \mathrm{i}=1, \ldots, n$ are the other estimations from the logistic regression analysis.

\subsection{Overall Survival}

The median follow-up was 12.3 months. The median survival rate was 12.8 months (95\% CI: 11.9; 14.3) for all the patients, while it was 20.8 months $(95 \%$ CI: 15.6; 23.5) for the Res group, 15 months (95\% CI: 12.8 ; 17.5) for the LA group, and 9.2 months (95\% CI: 8.2; 10.5) for the Met group. The one-year survival rate was $54.8 \%(95 \%$ CI: $50.0 ; 59.3)$ for all the patients and $76.4 \%$ (95\% CI: 66.6; 83.6) for those in the Res group, $60.5 \%$ (95\% CI: 52.3; 67.7) for those in the LA group, and 37.5\% (95\% CI: 30.5; 44.4) for those in the Met group (Figure 2). 


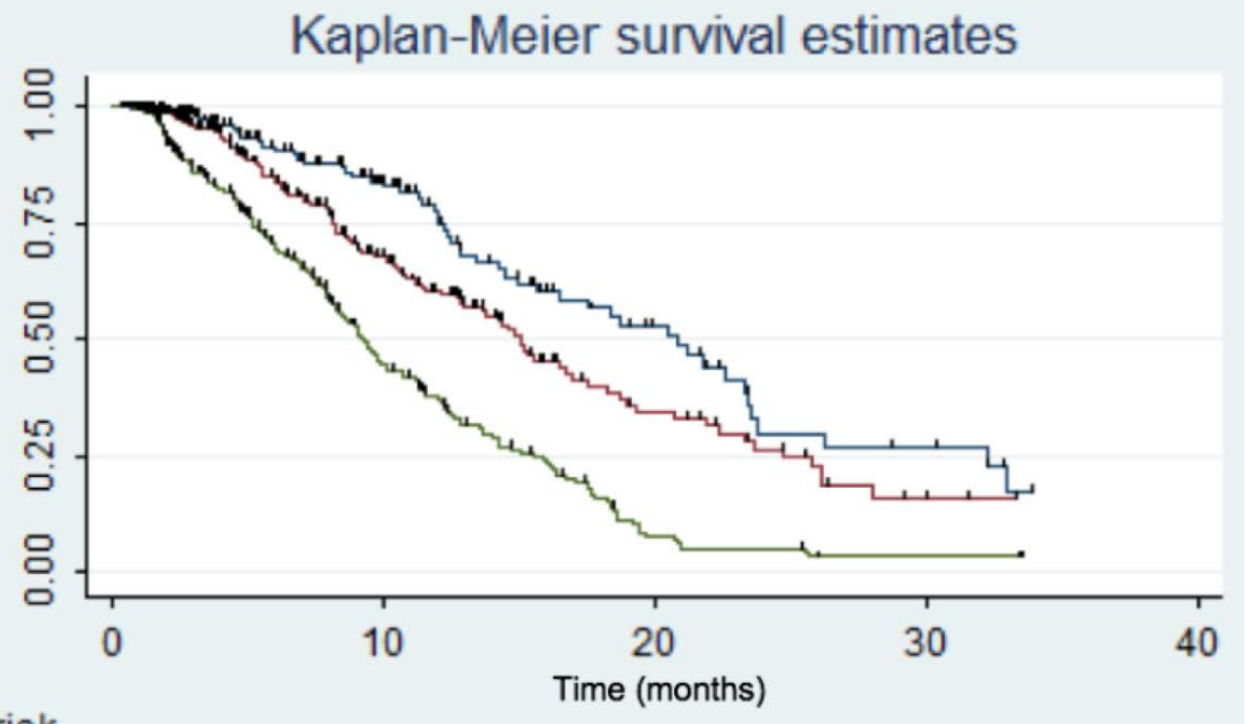

Number at risk

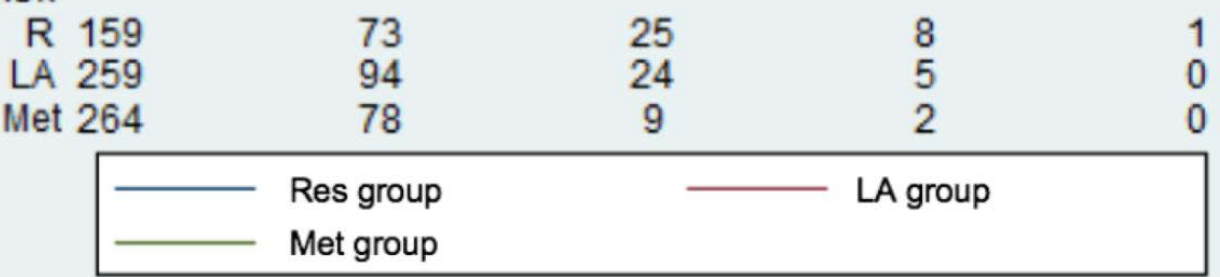

Figure 2. Kaplan-Meier survival estimates according to each group. Res: resectable; LA: locally advanced; Met: metastatic. Log-rank test: $p<0.001$.

According to the BACAP score, the median survival rate for the patients with a BACAP score $\leq$ 0.5 was 12.3 months (95\% CI: 10.7; 14.2), while it was 16.3 months $(95 \%$ CI: $14.0 ; 18.9)$ for the patients with a BACAP score $>0.5$ (Figure 3 ). The one-year survival rate for the patients with a BACAP score $\leq$ 0.5 was $51.4 \%(95 \%$ CI: $44.6 ; 57.7)$, while it was $69.8 \%(95 \%$ CI: $60.1 ; 77.6)$ for the patients with a BACAP score $>0.5$. 


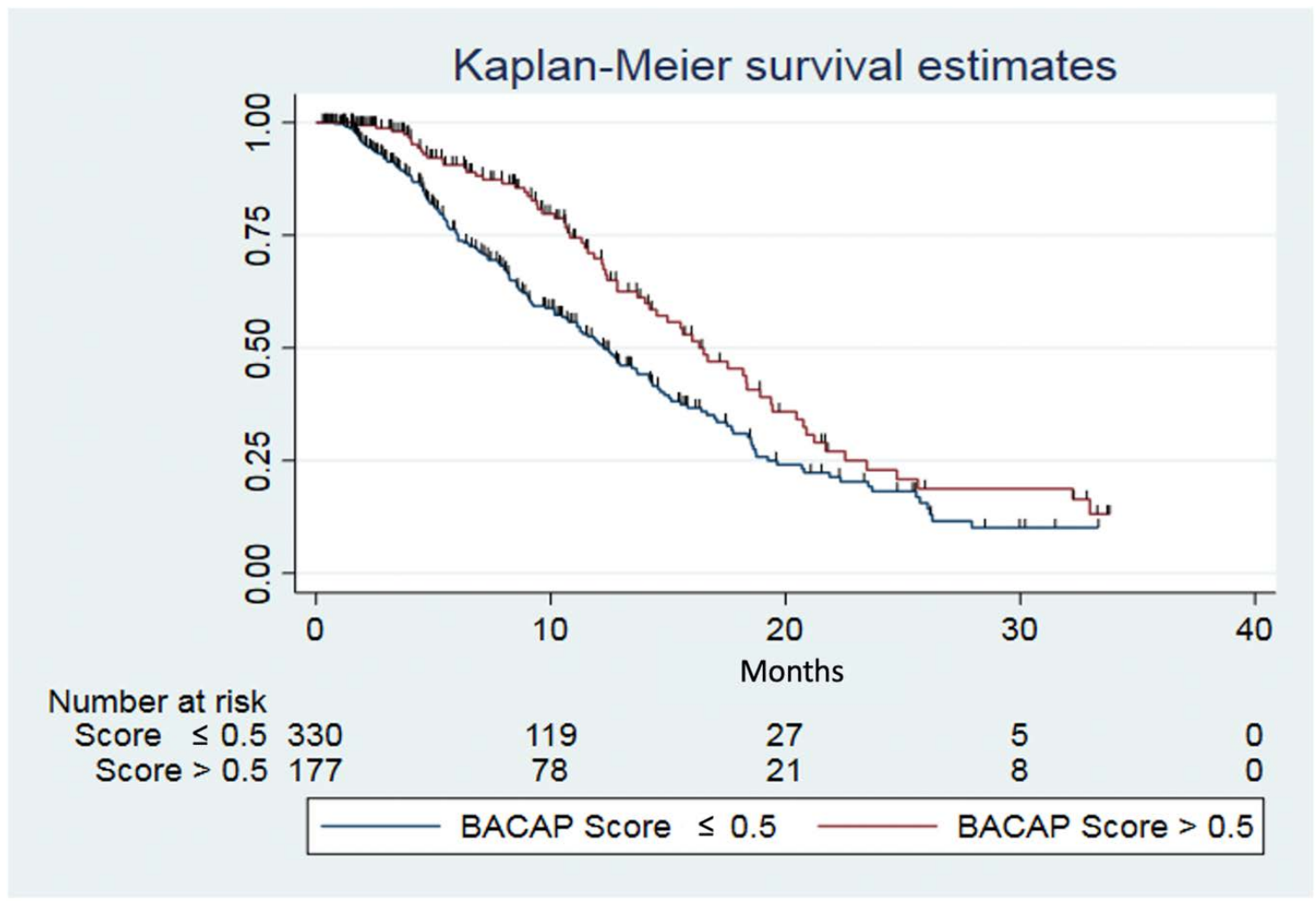

Figure 3. Kaplan-Meier survival estimates according the BACAP score. Log-rank test $(p=0.0012)$.

\section{Discussion}

Despite major advances in PDAC management, this disease remains a challenge for physicians due to the difficulty of early diagnosis. Among the various PDAC classifications in the literature [21], the most commonly used is the National Comprehensive Cancer Network (NCCN) system which classifies PDAC patients into three groups: resectable (including borderline resectable PDAC), locally advanced, and metastatic [22]. Vascular involvement of more or less than 180 degrees (with portomesenteric confluence, hepatic artery, celiac artery, or inferior vena cava) is the main factor that allows differentiation of the resectable group (including borderline tumors) from the locally advanced group [22]. The shortcoming of this classification is that it is only based on morphological criteria and does not include biological or clinical criteria, which leads to unnecessary laparotomies in as many as $30 \%$ of the PDAC patients considered to be resectable $[9,10]$. Therefore, we tried to determine the clinico-radiological predictive factors of resectability using the largest prospective multicentric cohort of PDAC patients to date with clinico-radiological and biological data described in the literature: the BACAP cohort.

Up until now, most studies that investigated the predictive factors of resectability were retrospective and monocentric, and they only assessed one or two criteria. In this study, we identified in multivariate analysis six clinico-radiological criteria that significantly reduced the probability of having a resectable tumor on diagnosis. These factors are well known to clinicians and are widely described in the literature; a large tumor size [18,23-25], location of the tumor in the body or tail [19,26-29], abdominal pain [30,31], weight loss $\geq 5-10 \%$ [32,33], venous or arterial thrombosis [34,35], and a poor performance status score (PS) [36-38] correlate with unresectability and poor survival of PDAC patients.

In the literature, only a few studies developed a score to predict resectability. These studies were monocentric, with a limited population, were mainly retrospective, and only used radiological criteria [39-41]. To date, only one study associated radiological criteria with tumor biomarkers to extend the basis of a predictive score [41]. Based on the multivariate analysis, we developed the first predictive scoring system to determine PDAC resectability, using both clinical and radiological 
criteria. This BACAP score allowed us to consider the patient as a whole and not limit ourselves to morphological criteria only. The main strengths of this score are its high efficiency and its ease of use with only six clinico-radiological criteria. For example, on diagnosis, a patient with no venous or arterial thrombosis, a performance status score of one, with abdominal pain, weight loss $\geq 8 \%$, and a tumor $\leq 20 \mathrm{~mm}$ located in the head of the pancreas has a $35 \%$ probability of being resectable. We would like to emphasize the importance of having such a tool in clinical practice to assist with the therapeutic decision in the context of a multidisciplinary meeting. However, this score still needs to be validated at the international level.

The main limitation of this study is the large amount of missing biological data. Therefore, Ca 19-9 and CEA were significant in univariate analysis but were no longer significant in multivariate analysis. Thus, these two biomarkers were not included in the BACAP score, although numerous authors showed that these biomarkers correlate with the prognosis and advanced stage disease $[3,17$, $42,43]$.

\section{Materials and Methods}

\subsection{Population}

Fifteen hospitals in France currently contribute data to the French BACAP prospective cohort. This biobank includes clinical, radiological, epidemiological, and social data linked to the biological samples. Patients with any stage of histologically and/or cytologically proven pancreatic ductal adenocarcinoma were included in the BACAP cohort on diagnosis and before treatment from May 2014 to July 2017. The design and management of the BACAP cohort were described in a previous article [20].

The patients were divided into three groups: the resectable (Res) group, the locally advanced (LA) group, and the metastatic (Met) group. The Res group included the patients for whom all the paraclinical examinations led to the conclusion of "resectable tumor" or "potentially resectable tumor" and who actually underwent surgery. The LA group included the patients for whom all the paraclinical examinations led to the conclusion of "locally advanced tumor". In this group, the CT scan or exploratory laparotomy revealed stomach, duodenal, colon, superior mesenteric artery, hepatic artery, coeliac trunk, superior mesenteric vein, portal vein, and splenic vein invasion. The Met group included the patients for whom all the paraclinical examinations led to the conclusion of "metastatic tumor". Liver metastasis or peritoneal carcinomatosis could be diagnosed during laparoscopy or laparotomy.

\subsection{Main Objective}

The main objective of this study was to develop a predictive score (the BACAP score) from clinical and radiological criteria to determine the probability of having a resectable PDAC on diagnosis.

\subsection{Data Collected}

For each patient, variables were collected prospectively and are detailed in a supplementary data table (Table S1). The initial data collected at inclusion were (1) sociodemographic data, (2) medical history, (3) symptoms on diagnosis, (4) biliary drainage, (5) description and characteristics of the pancreatic disease and the tumor, (6) biological analysis on diagnosis, (7) anatomopathological analysis, (8) treatment, and (9) delays. The WHO performance status score measures cancer patients' degree of autonomy: 0 (asymptomatic, fully active), 1 (restricted in physically activity but able to do everything else), and 2 (unable to work, out of bed more than $50 \%$ of the time during the day).

\subsection{Statistical Methods}

The population analyzed included the eligible patients who were previously classified in one of the three groups: resectable, locally advanced, or metastatic. Descriptive statistics were done of the entire population that was analyzed and in each group. The quantitative variables were described by the 
median and the range (minimum-maximum). The qualitative variables were described by the number of observations and the proportions. The number of missing values was reported, and the proportions calculated excluding missing values. The Kruskal-Wallis test was used to compare the distribution of the quantitative variables between the three groups. Proportions were compared between the three groups using chi-squared tests or Fisher's exact test when observations were at a low limit (expected cell count less than five). The variables that were significant at a level of $5 \%(p \leq 0.05)$ in the univariate analysis were selected for the multivariate analysis. To accomplish the main objective, the probability of belonging to the Res group vs. the LA or the Met group was calculated by multinomial logistic regression modeling. A multivariate logistic model with variables significant at a level of 5\% was used to devise the predictive score. We checked goodness of fit using the Hosmer-Lemeshow test and performed a link test to detect potential errors of model specification. The efficiency of the score was assessed by calculating the rate of correctly classified patients and the area under the receiver operating characteristic curve (ROC curve). The survival curves and rates were estimated with the Kaplan-Meier method, and the overall survival rates between the groups were compared using a log-rank test. All the statistical tests were bilateral with a significance level of $5 \%$. The statistical analyses were performed with STATA v13.0 (StataCorp LP, College Station, TX, USA).

\subsection{Ethics Statement and Consent to Participate}

All the patients were informed of the study and voluntarily consented in writing to being added to the BACAP cohort (Biological and Clinical Database for Pancreatic Adenocarcinoma). The biological collection was declared to and approved by the French Ministry of Research under number DC-2013-1974 and the database was mentioned in Clinical Trials under the following number: NCT02818829.

\section{Conclusions}

This study conducted in a large multicentric prospective cohort evaluated current management and outcomes of PDAC in France. We found six predictive clinico-radiological criteria of resectability that allowed us to devise a resectability scoring system that can be used on diagnosis. The BACAP score can be readily generated and will assist physicians with routine prediction of the resectability status of PDAC patients on diagnosis using straightforward criteria. The presence of adverse criteria or a BACAP score $<50 \%$ indicates that further investigations (such as MRI of the liver and of the pancreas, endoscopic ultrasound, repeat CT scan, etc.) are warranted to diagnose the PDAC more precisely, which could reduce the number of unwanted laparotomies. This would allow the patients to receive the best treatment or even a neoadjuvant treatment prior to resection.

Supplementary Materials: The following are available online at http://www.mdpi.com/2072-6694/12/4/783/s1: Table S1: Clinico-radiological and biological data collected.

Author Contributions: C.M., C.C., B.B., L.B., and F.M. made substantial contributions to the conceptualization and design, as well as to the acquisition, analysis, and interpretation of data. They participated in drafting and critical revision of the article for important intellectual content and approved the version to be published; B.N., L.P., N.F., G.P., P.G., S.T., and E.A. made substantial contributions to data acquisition and interpretation; C.T. and S.G. made substantial contributions to data analysis and interpretation. C.M., C.C., C.T., S.G., B.N., L.P., N.F., G.P., P.G., S.T., E.A., L.B., B.B., and F.M. participated in revising the article for important intellectual content and approved the version to be published. All authors have read and agreed to the published version of the manuscript.

Funding: Development of the BACAP was made possible by a grant from the French National Cancer Institute (INCa) through a proposal dedicated to a clinical and biological database in 2012 (Grant INCA_6294).

Acknowledgments: The authors wish to thank Jean Delpech for creating the website http://jdlp.fr/resectability/and the members of the BACAP consortium. BACAP consortium: ${ }^{1}$ Barbara Bournet, Cindy Canivet, Louis Buscail, Nicolas Carrère, Fabrice Muscari, Bertrand Suc, Rosine Guimbaud, Corinne Couteau, Marion Deslandres, Pascale Rivera, Anne-Pascale Laurenty, Nadim Fares, Etienne Buscail, Karl Barange, Janick Selves, Anne Gomez-Brouchet. 2 Bertrand Napoléon, Bertrand Pujol, Fabien Fumex, Jérôme Desrame, Christine Lefort, Vincent Lepilliez, Rodica Gincul, Pascal Artru, Léa Clavel, Anne-Isabelle Lemaistre. ${ }^{3}$ Laurent Palazzo; ${ }^{4}$ Jérôme Cros; ${ }^{5}$ Sarah Tubiana; 6 Nicolas Flori, Pierre Senesse, Pierre-Emmanuel Colombo, Emmanuelle Samail-Scalzi, Fabienne Portales, Sophie Gourgou, Claire Honfo Ga, Carine Plassot, Julien Fraisse, Frédéric Bibeau, Marc Ychou; ${ }^{7}$ Pierre Guibert, Christelle 
de la Fouchardière, Matthieu Sarabi, Patrice Peyrat, Séverine Tabone-Eglinger, Caroline Renard; ${ }^{8}$ Guillaume Piessen, Stéphanie Truant, Alain Saudemont, Guillaume Millet, Florence Renaud, Emmanuelle Leteurtre, Patrick Gele; ${ }^{9}$ Eric Assenat, Jean-Michel Fabre, François-Régis Souche, Marie Dupuy, Anne-Marie Gorce-Dupuy, Jeanne Ramos; ${ }^{10}$ Jean-François Seitz, Jean Hardwigsen, Emmanuelle Norguet-Monnereau, Philippe Grandval, Muriel Duluc, Dominique Figarella-Branger; ${ }^{11}$ Véronique Vendrely, Clément Subtil, Eric Terrebonne, Jean-Frédéric Blanc, Jean-Philippe Merlio; ${ }^{12}$ Dominique Farges-Bancel, Jean-Marc Gornet, Daniela Geromin; ${ }^{13}$ Geoffroy Vanbiervliet, Anne-Claire Frin, Delphine Ouvrier, Marie-Christine Saint-Paul; ${ }^{14}$ Philippe Berthelémy, Chelbabi Fouad; 15 Stéphane Garcia, Nathalie Lesavre, Mohamed Gasmi, Marc Barthet; ${ }^{16}$ Vanessa Cottet; ${ }^{17}$ Cyrille Delpierre.

${ }^{1}$ The CHU and the University of Toulouse, Toulouse, France; ${ }^{2}$ Jean Mermoz Hospital, Ramsay Général de Santé, Lyon, France; ${ }^{3}$ Trocadéro Clinic, Paris, France; ${ }^{4}$ The Department of Pathology, Beaujon Hospital and Paris 7 University, Clichy, France. ${ }^{5}$ The Biobank, Bichat Hospital and Paris 7 University, Paris, France; ${ }^{6}$ The Cancer Institute and the University of Montpellier, Montpellier, France; ${ }^{7}$ The Léon Bérard Cancer Center, Lyon, France; ${ }^{8}$ The Department of Digestive Surgery, the CHU and the University of Lille, Lille, France; ${ }^{9}$ The CHU and the University of Montpellier, Montpellier, France. ${ }^{10}$ La Timone Hospital and the University of Marseille, Marseille, France; ${ }^{11}$ The CHU and the University of Bordeaux, Bordeaux, France, ${ }^{12}$ Saint Louis Hospital and Paris 7 Diderot University, Paris, France, ${ }^{13}$ The CHU and the University of Nice, Nice, France; ${ }^{14}$ Pau Hospital, Pau, France; ${ }^{15}$ The CHU Nord Hospital and the University of Marseille, Marseille, France, ${ }^{16}$ INSERM UMR866 and the University of Dijon, Dijon, France, ${ }^{17}$ INSERM UMR1027 and the University of Toulouse, Toulouse France.

Conflicts of Interest: The authors declare no conflicts of interest.

\section{Abbreviations}

$\begin{array}{ll}\text { ALT } & \text { alanine aminotransferase } \\ \text { AST } & \text { aspartate aminotransferase } \\ \text { BACAP } & \text { National Anatomo-Clinical Database on Pancreatic Adenocarcinoma } \\ \text { CA19-9 } & \text { Carbohydrate antigen 19-9 } \\ \text { CEA } & \text { Carcinoembryonic antigen } \\ \text { CT-scan } & \text { Computed tomography scan } \\ \text { EUS } & \text { Endoscopic ultrasound } \\ \text { ERCP } & \text { Endoscopic retrograde cholangiopancreatography } \\ \text { INR } & \text { International Normalized Ratio } \\ \text { IPMN } & \text { Intraductal papillary mucinous neoplasm } \\ \text { LA } & \text { Locally advanced } \\ \text { Met } & \text { Metastatic } \\ \text { MRI } & \text { Magnetic resonance imaging } \\ \text { MTM } & \text { Multidisciplinary Team Meeting } \\ \text { PDAC } & \text { Pancreatic ductal adenocarcinoma } \\ \text { PET/CT } & \text { Positron emission tomography/computed tomography } \\ \text { PS } & \text { Performance status } \\ \text { Res } & \text { Resectable } \\ \text { ROC curve: } & \text { Receiver operating characteristic curve } \\ \text { TNM } & \text { Tumor node metastasis } \\ \text { WHO } & \text { World Health Organization }\end{array}$

\section{References}

1. Siegel, R.L.; Miller, K.D.; Jemal, A. Cancer statistics, 2016. CA Cancer J. Clin. 2016, 66, 7-30. [CrossRef]

2. Rahib, L.; Smith, B.D.; Aizenberg, R.; Rosenzweig, A.B.; Fleshman, J.M.; Matrisian, L. Projecting Cancer Incidence and Deaths to 2030: The Unexpected Burden of Thyroid, Liver, and Pancreas Cancers in the United States. Cancer Res. 2014, 74, 2913-2921. [CrossRef]

3. Neuzillet, C.; Gaujoux, S.; Williet, N.; Bachet, J.-B.; Bauguion, L.; Durand, L.C.; Conroy, T.; Dahan, L.; Gilabert, M.; Huguet, F.; et al. Pancreatic cancer: French clinical practice guidelines for diagnosis, treatment and follow-up (SNFGE, FFCD, GERCOR, UNICANCER, SFCD, SFED, SFRO, ACHBT, AFC). Dig. Liver Dis. 2018, 50, 1257-1271. [CrossRef] 
4. Bouvier, A.-M.; Uhry, Z.; Jooste, V.; Drouillard, A.; Remontet, L.; Launoy, G.; Leone, N.; (Francim), F.N.O.C.R. Focus on an unusual rise in pancreatic cancer incidence in France. Int. J. Epidemiol. 2017, 46, 1764-1772. [CrossRef]

5. Kommalapati, A.; Tella, S.H.; Goyal, G.; Ma, W.W.; Mahipal, A. Contemporary Management of Localized Resectable Pancreatic Cancer. Cancers 2018, 10, 24. [CrossRef]

6. Conroy, T.; Hammel, P.; Hebbar, M.; Ben Abdelghani, M.; Wei, A.C.; Raoul, J.-L.; Choné, L.; Francois, E.; Artru, P.; Biagi, J.J.; et al. FOLFIRINOX or Gemcitabine as Adjuvant Therapy for Pancreatic Cancer. N. Engl. J. Med. 2018, 379, 2395-2406. [CrossRef]

7. Von Hoff, D.D.; Ervin, T.; Arena, F.P.; Chiorean, E.G.; Infante, J.; Moore, M.; Seay, T.; Tjulandin, S.A.; Ma, W.W.; Saleh, M.N.; et al. Increased survival in pancreatic cancer with nab-paclitaxel plus gemcitabine. N. Engl. J. Med. 2013, 369, 1691-1703. [CrossRef]

8. Winter, J.M.; Brennan, M.; Tang, L.H.; D’Angelica, M.I.; DeMatteo, R.P.; Fong, Y.; Klimstra, D.S.; Jarnagin, W.R.; Allen, P.J. Survival after Resection of Pancreatic Adenocarcinoma: Results from a Single Institution over Three Decades. Ann. Surg. Oncol. 2011, 19, 169-175. [CrossRef]

9. Kneuertz, P.J.; Cunningham, S.C.; Cameron, J.L.; Torrez, S.; Tapazoglou, N.; Herman, J.M.; Makary, M.A.; Eckhauser, F.; Wang, J.; Hirose, K.; et al. Palliative Surgical Management of Patients with Unresectable Pancreatic Adenocarcinoma: Trends and Lessons Learned from a Large, Single Institution Experience. J. Gastrointest. Surg. 2011, 15, 1917-1927. [CrossRef]

10. Spanheimer, P.M.; Cyr, A.R.; Liao, J.; Johlin, F.C.; Hoshi, H.; Howe, J.R.; Mezhir, J.J. Complications and survival associated with operative procedures in patients with unresectable pancreatic head adenocarcinoma. J. Surg. Oncol. 2014, 109, 697-701. [CrossRef]

11. Marion-Audibert, A.-M.; Vullierme, M.-P.; Ronot, M.; Mabrut, J.-Y.; Sauvanet, A.; Zins, M.; Cuilleron, M.; Cunha, A.S.; Lévy, P.; Rode, A. Routine MRI With DWI Sequences to Detect Liver Metastases in Patients With Potentially Resectable Pancreatic Ductal Carcinoma and Normal Liver CT: A Prospective Multicenter Study. Am. J. Roentgenol. 2018, 211, W217-W225. [CrossRef] [PubMed]

12. Tas, F.; Aykan, F.; Alici, S.; Kaytan, E.; Aydiner, A.; Topuz, E. Prognostic factors in pancreatic carcinoma: Serum LDH levels predict survival in metastatic disease. Am. J. Clin. Oncol. 2001, 24. [CrossRef] [PubMed]

13. Chiang, K.-C.; Yeh, C.-N.; Ueng, S.-H.; Hsu, J.-T.; Yeh, T.-S.; Jan, Y.-Y.; Hwang, T.-L.; Chen, M.-F. Clinicodemographic aspect of resectable pancreatic cancer and prognostic factors for resectable cancer. World J. Surg. Oncol. 2012, 10, 77. [CrossRef]

14. Katz, M.H.G.; Varadhachary, G.R.; Fleming, J.B.; Wolff, R.A.; Lee, J.E.; Pisters, P.W.T.; Vauthey, J.-N.; Abdalla, I.K.; Sun, C.C.; Wang, H.; et al. Serum CA 19-9 as a marker of resectability and survival in patients with potentially resectable pancreatic cancer treated with neoadjuvant chemoradiation. Ann. Surg. Oncol. 2010, 17, 1794-1801. [CrossRef]

15. Maithel, S.K.; Maloney, S.; Winston, C.; Gonen, M.; D’Angelica, M.I.; DeMatteo, R.P.; Jarnagin, W.R.; Brennan, M.; Allen, P.J. Preoperative CA 19-9 and the Yield of Staging Laparoscopy in Patients with Radiographically Resectable Pancreatic Adenocarcinoma. Ann. Surg. Oncol. 2008, 15, 3512-3520. [CrossRef]

16. Schlieman, M.G.; Ho, H.S.; Bold, R.J. Utility of Tumor Markers in Determining Resectability of Pancreatic Cancer. Arch. Surg. 2003, 138, 951. [CrossRef]

17. Ferrone, C.R.; Finkelstein, D.M.; Thayer, S.P.; Muzikansky, A.; Castillo, C.F.-D.; Warshaw, A.L. Perioperative CA19-9 Levels Can Predict Stage and Survival in Patients With Resectable Pancreatic Adenocarcinoma. J. Clin. Oncol. 2006, 24, 2897-2902. [CrossRef]

18. Agarwal, B.; Correa, A.M.; Ho, L. Survival in Pancreatic Carcinoma Based on Tumor Size. Pancreas 2008, 36, e15-e20. [CrossRef]

19. Van Erning, F.N.; Mackay, T.M.; van der Geest, L.G.; Groot Koerkamp, B.; van Laarhoven, H.W.; Bonsing, B.A.; Wilmink, J.W.; van Santvoort, H.C.; de Vos-Geelen, J.; van Eijck, C.H.; et al. Association of the location of pancreatic ductal adenocarcinoma (head, body, tail) with tumor stage, treatment, and survival: A population-based analysis. Acta Oncol. 2018, 57, 1655-1662. [CrossRef]

20. Canivet, C.; The BACAP Consortium; Gourgou-Bourgade, S.; Napoléon, B.; Palazzo, L.; Flori, N.; Guibert, P.; Piessen, G.; Farges-Bancel, D.; Seitz, J.-F.; et al. A prospective clinical and biological database for pancreatic adenocarcinoma: The BACAP cohort. BMC Cancer 2018, 18, 1-8. [CrossRef] 
21. Zaky, A.M.; Wolfgang, C.L.; Weiss, M.; Javed, A.A.; Fishman, E.K.; Zaheer, A. Tumor-Vessel Relationships in Pancreatic Ductal Adenocarcinoma at Multidetector CT: Different Classification Systems and Their Influence on Treatment Planning. Radiographic 2017, 37, 93-112. [CrossRef] [PubMed]

22. Tempero, M.A.; Malafa, M.P.; Al-Hawary, M.; Asbun, H.; Bain, A.; Behrman, S.W.; Benson, A.B.; Binder, E.; Cardin, D.B.; Cha, C.; et al. Pancreatic Adenocarcinoma, Version 2.2017, NCCN Clinical Practice Guidelines in Oncology. J. Natl. Compr. Cancer Netw. 2017, 15, 1028-1061. [CrossRef] [PubMed]

23. Li, D.; Hu, B.; Zhou, Y.; Wan, T.; Si, X. Impact of tumor size on survival of patients with resected pancreatic ductal adenocarcinoma: A systematic review and meta-analysis. BMC Cancer 2018, 18, 985. [CrossRef] [PubMed]

24. Marchegiani, G.; Andrianello, S.; Malleo, G.; De Gregorio, L.; Scarpa, A.; Mino-Kenudson, M.; Maggino, L.; Ferrone, C.; Lillemoe, K.; Bassi, C.; et al. Does size matter in pancreatic cancer? Reappraisal of tumour dimension as a predictor of outcome beyond the TNM. Pancreatology. 2016, 16, S46. [CrossRef]

25. Hong, S.B.; Lee, S.S.; Kim, J.H.; Kim, H.J.; Byun, J.H.; Hong, S.-M.; Song, K.-B.; Kim, S.C. Pancreatic Cancer CT: Prediction of Resectability according to NCCN Criteria. Radiology 2018, 289, 710-718. [CrossRef]

26. Brennan, M.; Moccia, R.D.; Klimstra, D. Management of Adenocarcinoma of the Body and Tail of the Pancreas. Ann. Surg. 1996, 223, 506-512. [CrossRef]

27. Sperti, C.; Pasquali, C.; Pedrazzoli, S. Ductal adenocarcinoma of the body and tail of the pancreas. J. Am. Coll. Surg. 1997, 185, 255-259. [CrossRef]

28. Zhang, D.-X.; Dai, Y.-D.; Yuan, S.-X.; Tao, L. Prognostic factors in patients with pancreatic cancer. Exp. Ther. Med. 2011, 3, 423-432. [CrossRef]

29. Dreyer, S.; Jamieson, N.B.; Upstill-Goddard, R.; Bailey, P.; McKay, C.J.; Biankin, A.V.; Chang, D. Defining the molecular pathology of pancreatic body and tail adenocarcinoma. BJS 2018, 105, e183-e191. [CrossRef]

30. Koulouris, A.I.; Banim, P.; Hart, A.R. Pain in Patients with Pancreatic Cancer: Prevalence, Mechanisms, Management and Future Developments. Dig. Dis. Sci. 2017, 62, 861-870. [CrossRef]

31. Müller, M.W.; Friess, H.; Köninger, J.; Martín, D.; Wente, M.; Hinz, U.; Ceyhan, G.O.; Blaha, P.; Kleeff, J.; Büchler, M.W. Factors influencing survival after bypass procedures in patients with advanced pancreatic adenocarcinomas. Am. J. Surg. 2008, 195, 221-228. [CrossRef] [PubMed]

32. DeWys, W.D.; Begg, C.; Lavin, P.T.; Band, P.R.; Bennett, J.M.; Bertino, J.R.; Cohen, M.H.; O Douglass, H.; Engstrom, P.F.; Ezdinli, E.Z.; et al. Prognostic effect of weight loss prior to chemotherapy in cancer patients. Eastern Cooperative Oncology Group. Am. J. Med. 1980, 69. [CrossRef]

33. Chauffert, B.; Mornex, F.; Bonnetain, F.; Rougier, P.; Mariette, C.; Bouche, O.; Bosset, J.F.; Aparicio, T.; Mineur, L.; Azzedine, A.; et al. Phase III trial comparing intensive induction chemoradiotherapy (60 Gy, infusional 5-FU and intermittent cisplatin) followed by maintenance gemcitabine with gemcitabine alone for locally advanced unresectable pancreatic cancer. Definitive results of the 2000-01 FFCD/SFRO study. Ann. Oncol. 2008, 19, 1592-1599. [PubMed]

34. Blom, J.; Osanto, S.; Rosendaal, F. High risk of venous thrombosis in patients with pancreatic cancer: A cohort study of 202 patients. Eur. J. Cancer 2006, 42, 410-414. [CrossRef]

35. Frere, C.; Bournet, B.; Gourgou, S.; Fraisse, J.; Canivet, C.; Connors, J.M.; Buscail, L.; Farge, D.; Carrère, N.; Muscari, F.; et al. Incidence of Venous Thromboembolism in Patients With Newly Diagnosed Pancreatic Cancer and Factors Associated With Outcomes. Gastroenterology 2019. [CrossRef]

36. Louvet, C.; Labianca, R.; Hammel, P.; Lledo, G.; Zampino, M.; Andre, T.; Zaniboni, A.; Ducreux, M.; Aitini, E.; Taïeb, J.; et al. Gemcitabine in Combination With Oxaliplatin Compared With Gemcitabine Alone in Locally Advanced or Metastatic Pancreatic Cancer: Results of a GERCOR and GISCAD Phase III Trial. J. Clin. Oncol. 2005, 23, 3509-3516. [CrossRef]

37. Tas, F.; Sen, F.; Odabas, H.; Kılıc, L.; Keskın, S.; Yıldız, I.; Kilic, L.I. Performance status of patients is the major prognostic factor at all stages of pancreatic cancer. Int. J. Clin. Oncol. 2012, 18, 839-846. [CrossRef]

38. Bilici, A. Prognostic factors related with survival in patients with pancreatic adenocarcinoma. World J. Gastroenterol. 2014, 20, 10802-10812. [CrossRef]

39. Toesca, D.A.S.; Jeffrey, R.B.; Von Eyben, R.; Pollom, E.L.; Poullos, P.D.; Poultsides, G.A.; Fisher, G.A.; Visser, B.C.; Koong, A.C.; Chang, D.T. Predicting Pancreatic Cancer Resectability and Outcomes Based on an Objective Quantitative Scoring System. Pancreas 2019, 48, 622-628. [CrossRef] 
40. Klauss, M.; Mohr, A.; Von Tengg-Kobligk, H.; Friess, H.; Singer, R.; Seidensticker, P.; Kauczor, H.; Richter, G.; Kauffmann, G.; Grenacher, L. A New Invasion Score for Determining the Resectability of Pancreatic Carcinomas with Contrast-Enhanced Multidetector Computed Tomography. Pancreatology 2008, 8, 204-210. [CrossRef]

41. Watanabe, S.; Kobayashi, N.; Kubota, K.; Sato, T.; Kato, S.; Hosono, K.; Shimamura, T.; Inayama, Y.; Nakajima, A.; Endo, I. A novel scoring system for arterial invasion of pancreatic body and tail cancer based on multidetector row computed tomography and biomarkers. Pancreatology 2013, 13, 161-169. [CrossRef] [PubMed]

42. Mirkin, K.A.; Hollenbeak, C.S.; Wong, J. Prognostic impact of carbohydrate antigen 19-9 level at diagnosis in resected stage I-III pancreatic adenocarcinoma: A U.S. population study. J. Gastrointest. Oncol. 2017, 8, 778-788. [CrossRef] [PubMed]

43. Imaoka, H.; Mizuno, N.; Hara, K.; Hijioka, S.; Tajika, M.; Tanaka, T.; Ishihara, M.; Hirayama, Y.; Hieda, N.; Yoshida, T.; et al. Prognostic impact of carcinoembryonic antigen (CEA) on patients with metastatic pancreatic cancer: A retrospective cohort study. Pancreatology 2016, 16, 859-864. [CrossRef]

(C) 2020 by the authors. Licensee MDPI, Basel, Switzerland. This article is an open access article distributed under the terms and conditions of the Creative Commons Attribution (CC BY) license (http://creativecommons.org/licenses/by/4.0/). 